\title{
Erratum to: Enhanced tolerance of transgenic tall fescue plants overexpressing 2-Cys peroxiredoxin against methyl viologen and heat stresses
}

\author{
Kyung-Hee Kim • Iftekhar Alam • Ki-Won Lee • \\ Shamima Akhtar Sharmin · Sang-Soo Kwak • \\ Sang Yeol Lee $\cdot$ Byung-Hyun Lee
}

Published online: 7 January 2010

(C) Springer Science+Business Media B.V. 2010

\section{Erratum to: Biotechnol Lett \\ DOI 10.1007/s10529-009-0185-0}

Unfortunately, author's address has been mistakenly published in the original article. The correct version of the author's address is provided in this erratum article.

The online version of the original article can be found under doi:10.1007/s10529-009-0185-0.

K.-H. Kim · I. Alam · K.-W. Lee · S. A. Sharmin · S. Y. Lee · B.-H. Lee $(\bowtie)$

Division of Applied Life Sciences (BK21 Program), IALS, PMBBRC, Gyeongsang National University,

Jinju 660-701, Korea

e-mail: hyun@gnu.ac.kr

\section{S.-S. Kwak}

Environmental Biotechnology Research Center, Korea

Research Institute of Bioscience and Biotechnology

(KRIBB), Daejeon 305-806, Korea 